Review

\title{
Preventive Role of Diet Interventions and Dietary Factors in Type 2 Diabetes Mellitus: An Umbrella Review
}

\author{
Phung Lam Toi ${ }^{1,2,+} \oplus$, Thunyarat Anothaisintawee ${ }^{1,3, *,+}$, Usa Chaikledkaew ${ }^{1,4}{ }^{1}$, \\ Jamaica Roanne Briones ${ }^{1}$, Sirimon Reutrakul ${ }^{5}\left[\right.$ and Ammarin Thakkinstian ${ }^{1,6}$ \\ 1 Mahidol University Health Technology Assessment (MUHTA) Graduate Program, Mahidol University, \\ Bangkok 10400, Thailand; phunglamtoi@hspi.org.vn (P.L.T.); usa.chi@mahidol.ac.th (U.C.); \\ jambriones@gmail.com (J.R.B.); ammarin.tha@mahidol.edu (A.T.) \\ 2 Health Strategy and Policy Institute, Ministry of Health, Hanoi 10400, Vietnam \\ 3 Department of Family Medicine, Ramathibodi Hospital, Mahidol University, Bangkok 10400, Thailand \\ 4 Social Administrative Pharmacy Division, Department of Pharmacy, Faculty of Pharmacy, \\ Mahidol University, Bangkok 10400, Thailand \\ 5 Division of Endocrinology, Diabetes and Metabolism, Department of Medicine, University of Illinois College \\ of Medicine at Chicago, 835 S Wolcott, Ste E625, Chicago, IL 60612, USA; sreutrak10800@gmail.com \\ 6 Department of Clinical Epidemiology and Biostatistics, Ramathibodi Hospital, Mahidol University, \\ Bangkok 10400, Thailand \\ * Correspondence: thunyarat.ano@mahidol.ac.th; Tel.: +662-201-1406; Fax: +662-201-1486 \\ + P.L.T. and T.A. contribute equally to this work.
}

Received: 21 July 2020; Accepted: 2 September 2020; Published: 6 September 2020

\begin{abstract}
Background: Although the body of evidence indicates clear benefits of dietary modifications for prevention of type-2 diabetes mellitus (T2DM), it may be difficult for healthcare providers to recommend which diet interventions or dietary factors are appropriate for patients as there are too many modalities available. Accordingly, we performed an umbrella review to synthesize evidence on diet interventions and dietary factors in prevention of T2DM. Methods: Medline and Scopus databases were searched for relevant studies. Systematic reviews with meta-analyses of randomized-controlled trial or observational studies were eligible if they measured effects of diet interventions and/or dietary factors including dietary patterns, food groups, and nutrients on risk of T2DM. The effect of each diet intervention/factor was summarized qualitatively. Results: Sixty systematic reviews and meta-analyses were eligible. Results of the review suggest that healthy dietary patterns such as Mediterranean and Dietary Approaches to Stop Hypertension (DASH) diets, and high consumption of whole grains, low-fat dairy products, yogurt, olive oil, chocolate, fiber, magnesium, and flavonoid significantly reduced the risk of T2DM. In contrast, high glycemic index and glycemic load diets, high consumption of red and processed meat, and sugar or artificial sugar-sweetened beverages significantly increased risk of T2DM. Prescribing diet interventions with or without physical activity interventions significantly decreased risk of T2DM in both high-risk and general population. Conclusion: High consumption of Mediterranean and DASH diet, and interventions that modified the quality of diet intake significantly reduced risk of T2DM especially in the high-risk population. These lifestyle modifications should be promoted in both individual and population levels to prevent and decrease burden from $\mathrm{T} 2 \mathrm{DM}$ in the future.
\end{abstract}

Keywords: diabetes mellitus; dietary patterns; nutrient; food; systematic review 


\section{Introduction}

Type-2 diabetes mellitus (T2DM) is a major public health problem. Around 425 million people globally were diagnosed with T2DM in 2017 and this is predicted to increase to 629 million by 2045 [1]. T2DM is also a significant risk factor of cardiovascular diseases, the leading cause of morbidity and mortality in population worldwide [2]. Moreover, the economic burden on T2DM contributes to approximately $12 \%$ of global health expenditure from diabetic treatment and its complications [1]. As such, there is an urgency to decrease the global health and economic burden related to T2DM.

Genetic and lifestyle factors, especially diet, are significant determinants of T2DM. Lifestyle factors are modifiable and thus should be the focus in the effort to lower T2DM risk [3]. Several systematic reviews and meta-analyses (SRMA) of randomized controlled trials (RCT) [4-6] indicated that interventions that modified diet quality (e.g., low calories and low-fat diet) and/or enhanced level of physical activity can delay or prevent the onset of T2DM. However, the evidence focused only on high-risk population such as people with prediabetes or obesity. In the general population, evidence on the benefit of lifestyle factors were mostly based on observational studies that measured the association between lifestyle factors (e.g., dietary factors and level of physical activity) and risk of T2DM. Dietary factors can be divided into many sub-categories such as dietary patterns (e.g., Mediterranean and Dietary Approaches to Stop Hypertension (DASH) diet), food groups (e.g., nuts, whole grains, vegetables, fruits), and food nutrients. Several SRMAs investigated the effect of dietary factors on risk of T2DM. However, some of this evidence shows conflicting results. For instance, three SRMAs [7-9] assessing the effect of a high intake of dairy products demonstrated significant benefits for T2DM prevention, whereas the other 2 SRMAs [10,11] showed non-significant benefits.

Therefore, a comprehensive review is essential to summarize the effect of dietary factors and diet interventions on T2DM risk. In addition, a thorough review of the quality of previous evidence is necessary before making a strong conclusion about the benefit of dietary factors and diet interventions in the prevention of T2DM. As such, we performed an umbrella review aiming to comprehensively summarize all available evidence of the effect of dietary factors (e.g., dietary patterns, food groups, and nutrients) and diet interventions on the risk of T2DM in both general and high-risk population. The results from this review should be beneficial for health care providers and policymakers in applying them in clinical and public health practices.

\section{Materials and Methods}

The methodology of this umbrella review was done in adherence to the proposal registered in PROSPERO (CRD42018105292). This review was also conducted according to the preferred reporting items for systematic reviews and meta-analyses (PRISMA) guidelines [12].

\subsection{Location of Studies}

PubMed and Scopus databases were searched for relevant studies from inceptions until August 2020. Search terms and search strategies for each database are described in Supplementary Tables S1 and S2. Reference lists of included systematic reviews were explored. We also contacted experts in this field for potentially relevant studies.

\subsection{Selection of Studies}

Two authors (P.L.T. and J.R.B.) independently selected studies. Percent agreement between two reviewers was $92.68 \%$ with kappa statistic of 0.83 . SRMAs of randomized controlled trials (RCT) or observational studies published in any language were eligible if the study's participants were nondiabetic adults aged greater than 18 years, exposures or interventions were dietary factors (e.g., dietary patterns, food groups, and nutrients), diet intervention, or combined lifestyle interventions that included diet intervention, and had evaluated the incidence of T2DM for the outcome. Studies were excluded if the study compared diet interventions with pharmacological interventions. 


\subsection{Data Extraction}

Two authors (P.L.T. and T.A.) independently extracted data including general information, review methodology (i.e., review question according to participants $(\mathrm{P})$, interested intervention/exposure (I), comparator $(\mathrm{C})$, interested outcome $(\mathrm{O})$, and study design of included studies, number of databases used for searching, last searched date, number of included studies), characteristics of included studies (setting, participants, sample size, interventions/comparators, and outcomes), and findings (i.e., pooled risk ratio $(\mathrm{RR})$, odds ratio $(\mathrm{OR})$, and hazard ratio (HR), along with their $95 \%$ confidence intervals $(\mathrm{CI})$, heterogeneity, and publication bias). Disagreement of data extraction between the two reviewers was resolved by discussion with a third-party reviewer (U.C., A.T.).

\subsection{Risk of Bias Assessment}

The quality of SRMAs was assessed by Assessing the Methodological Quality of Systematic Reviews-2 (AMSTAR-2) [13], instead of A Risk of Bias Assessment Tool for Systematic Reviews (ROBIS) as stated in the review proposal, because the AMSTAR-2 is a more updated tool that applies to SRMA of non-RCTs [13].

AMSTAR-2 involves critical and non-critical domains. The critical domains consist of seven items (i.e., protocol registration, adequacy of literature search, justification of excluding studies, performing risk of bias assessment, appropriateness of meta-analytical method, consideration of risk of bias when interpreting the results, and assessment of publication bias). The rest of the nine items are non-critical domains. Each item was graded as yes, partial yes, and no, if the SRMA completely, partially, and did not comply with that criteria, respectively. The overall quality of the SRMA was then graded as "high confidence" if the SRMA complied with all items of critical and noncritical domains, or only one noncritical domain was violated; "moderate confidence" if the SRMA complied with all critical domains but more than one noncritical domains were violated; "low and critically low confidence," if one and more than one critical domains were violated regardless noncritical domain [13]. Two authors (P.L.T., T.A.) independently assessed the quality of each study and discrepancies between the two authors were solved by consensus and discussion (U.C., A.T.).

\subsection{Data Synthesis}

The characteristics of the included SRMAs were qualitatively summarized. In addition, specific characteristics of meta-analysis were also described including type of meta-analysis (direct or network meta-analyses), parameter used for pooling, results of heterogeneity between studies and publication bias assessment.

The study matrix was constructed considering individual included studies of each SRMA in row across each meta-analysis in columns. Each study may be included in each meta-analysis more than once, thus form overlapping evidence. A degree of overlapping was therefore assessed by calculation of the corrected covered area (CCA) for each type of intervention [14]. The CCA ranging from $0 \%$ to $5 \%$ suggested the slight degree of overlapping, while CCA ranging from 6-10\%, 11-15\%, and greater than $15 \%$ indicated the moderate, high, and very high overlapping, respectively. Furthermore, an excess significant finding (ESF) was estimated [15] to assess if the individual meta-analyses were over-claimed. Finally, forest plots of the effects of dietary factors and diet interventions from good quality SRMAs or the most recent ones were constructed.

STATA 15.0 (Stata Corp, College Station, TX, USA) was utilized for constructing forest plot as well as in measuring excess significant finding.

\section{Results}

A total of 3408 articles were identified which yielded 60 eligible SRMAs for the umbrella review (Figure 1). Characteristics of included SRMAs are summarized in Supplementary Table S3. These studies were published between 2005 and 2020. The number of databases used ranged from 1 to 13 
with a median of 3 . Number of included individual studies ranged from 3 to 88 with a median of 10 studies.
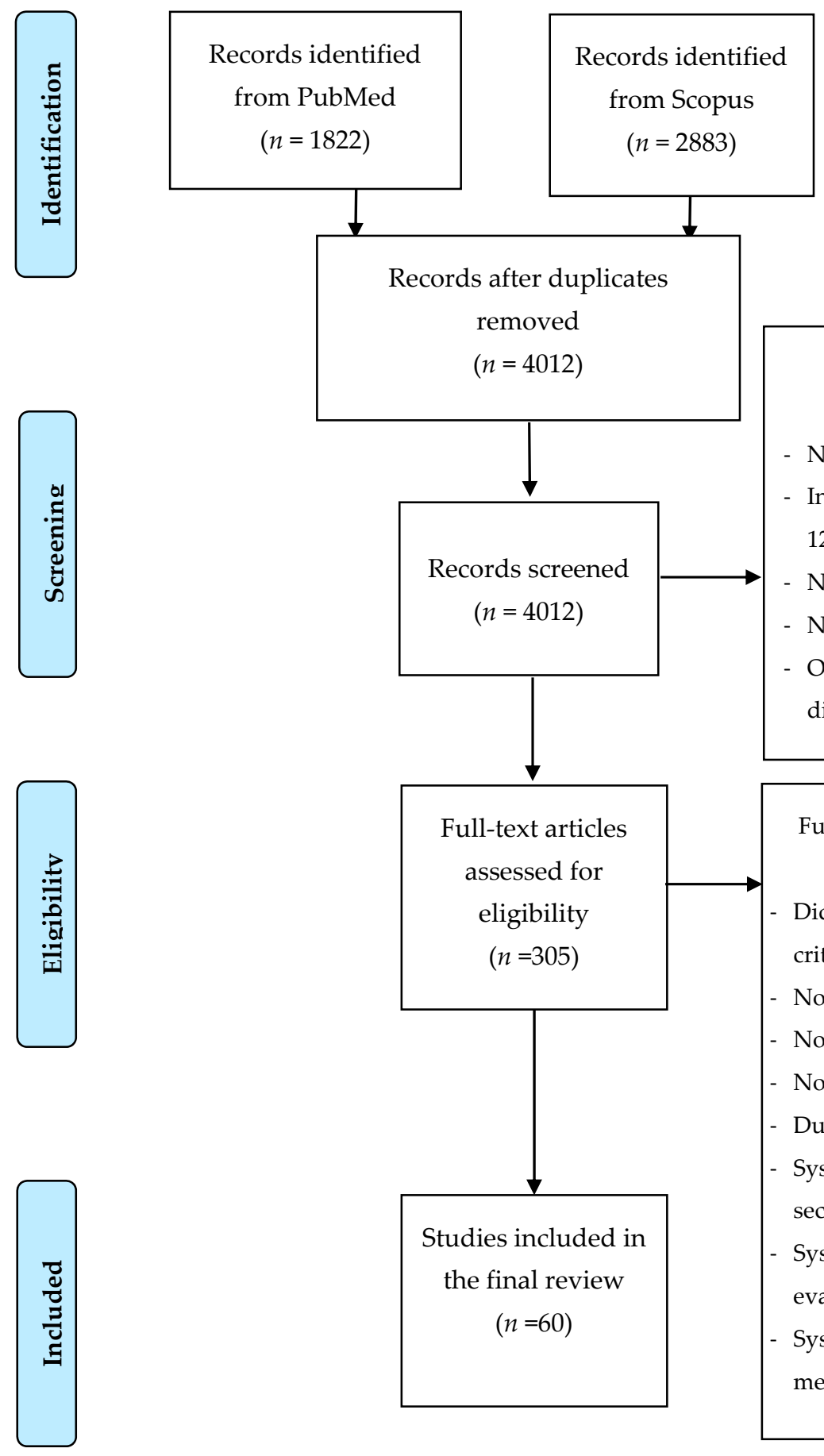

Records after duplicates

removed

$(n=4012)$
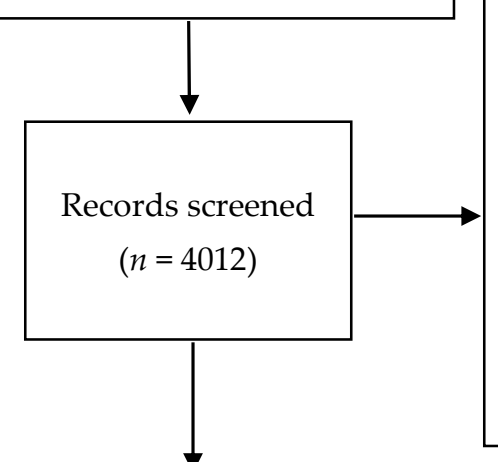

Not target Population: 874

- Inappropriate Intervention: 1269

- Not interested outcome: 922

- Not systematic review: 62

- Others (editorial, not relevant diseases): 580

\begin{tabular}{|c|c|}
\hline $\begin{array}{l}\text { Full-text articles } \\
\text { assessed for }\end{array}$ & $\begin{array}{l}\text { Full-text articles excluded, with } \\
\text { reasons }(n=245)\end{array}$ \\
\hline $\begin{array}{l}\text { eligibility } \\
(n=305)\end{array}$ & $\begin{array}{l}\text { - Did not meet systematic review } \\
\text { criteria: } 130 \\
\text { - Not target Population: } 12\end{array}$ \\
\hline$\downarrow$ & $\begin{array}{l}\text { - Not interested intervention: } 29 \\
\text { - Not interested outcome: } 34 \\
\text { - Duplicates, withdrawn: } 9 \\
\text { - Systematic reviews of cross- }\end{array}$ \\
\hline $\begin{array}{l}\text { Studies included in } \\
\text { the final review } \\
\qquad(n=60)\end{array}$ & $\begin{array}{l}\text { sectional study: } 7 \\
\text { - Systematic reviews of economic } \\
\text { evaluation: } 4 \\
\text { - Systematic reviews without } \\
\text { meta-analysis: } 20\end{array}$ \\
\hline
\end{tabular}

Figure 1. Flow diagram of study selection.

SRMAs were mainly conducted in Europe (21/60), followed by Asia (16/60), U.K (10/60), and the U.S. (10/60). Government was the main source of funding (27/60), whereas 18\% (11/60) of included SRMAs did not report the funding source. Most of SRMAs reported no conflict of interest (48/60). All SRMAs applied pairwise meta-analysis for pooling effect sizes, except one that utilized a network meta-analysis of RCT [16]. The diet interventions and dietary factors were re-categorized into five groups, namely dietary patterns, food groups, food nutrients, diet interventions, and combined diet 
and physical activity interventions. Eighteen studies were SRMAs of RCTs, while forty-two studies were SRMAs of observational studies. Studies that considered diet interventions and combined diet and physical activity interventions were only SRMAs of RCTs, while almost all studies considering dietary factors as interested exposures were SRMAs of cohort studies.

\subsection{Dietary Factors}

Forty-three SRMAs assessed the effects of dietary factors. Dietary factors were classified into food groups, food nutrients, and dietary patterns. Characteristics of the included SRMAs are presented in Supplementary Table S3.

\subsubsection{Food Groups}

Twenty-four SRMAs of cohort studies assessed the effect of food groups on risk of T2DM. Study's participants were the general population for all SRMAs. The effects of each food group are presented in Figure 2 and Supplementary Table S4.

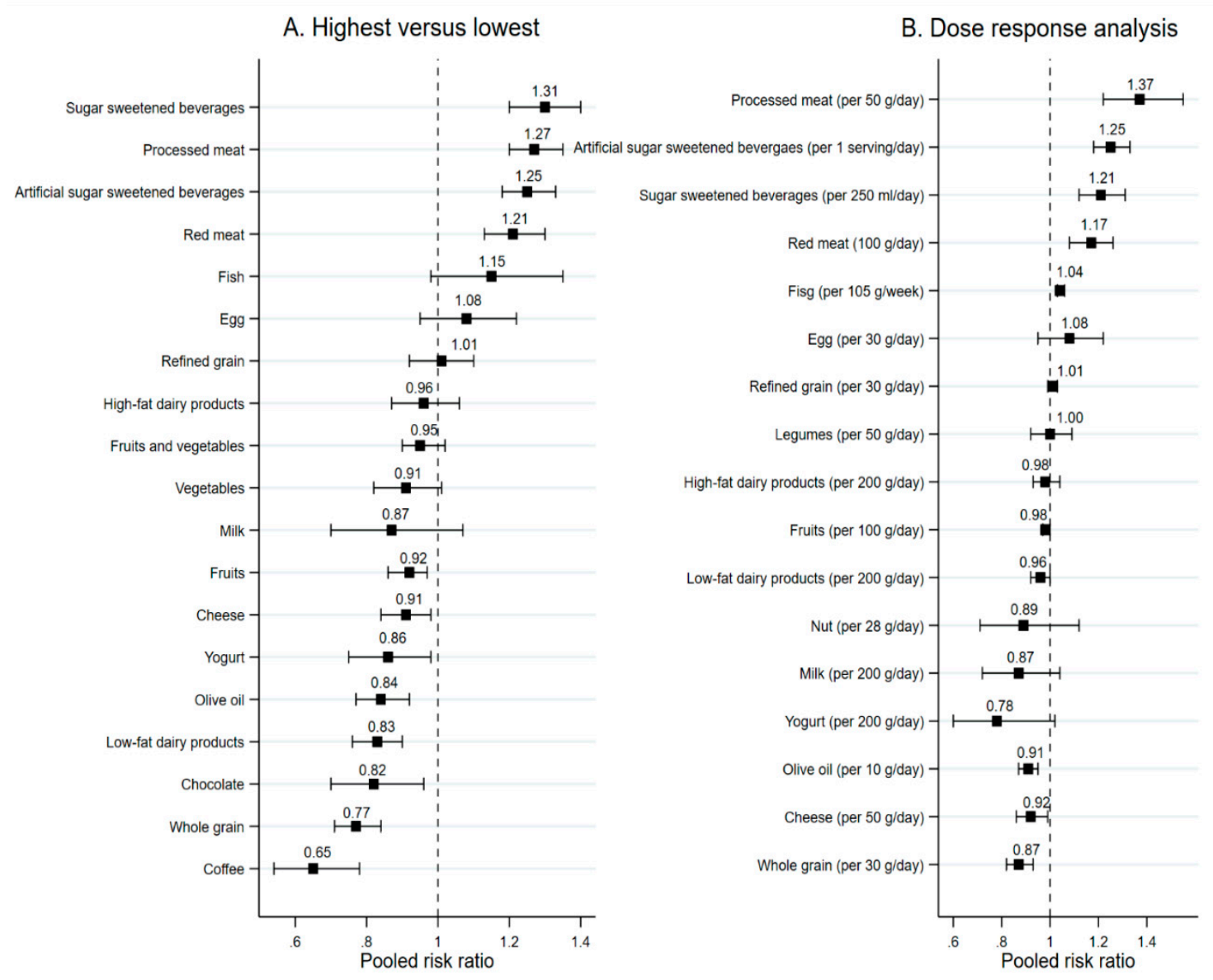

Figure 2. Pooled risk ratios of food groups and risk of T2DM. (A) Highest versus lowest category comparison. (B) Dose-response analysis.

Fruits and Vegetables

Results from four SRMAs [17-20] found that compared to low intake, high fruit and vegetable intake did not significantly lower the risk of T2DM with pooled RRs ranging from 0.93 (95\% CI: $0.87,1.00)$ to $1(95 \%$ CI: $0.92,1.09)$, see Figure $2 \mathrm{~A}$. When considering vegetable and fruit separately, high vegetable intake did not significantly lower the risk of T2DM, but the evidence for high fruit intake were inconsistent. Two SRMAs found non-significant benefits of high fruit intake, while one 
SRMA suggested that high fruit intake significantly decreased the risk of T2DM with pooled RR of 0.92 (95\% CI: 0.86, 0.97) [21].

Whole and Refined Grains, Nuts, and Legumes

Results from four SRMAs of cohort studies [9,22-24] found that high whole-grain intake significantly decreased the risk of T2DM with pooled RR ranging from 0.74 (95\% CI: $0.69,0.80$ ) to 0.79 (95\% CI: $0.72,0.87)$, see Figure 2A. In addition, every $30 \mathrm{~g} /$ day increase in an intake of whole-grain significantly reduced the risk of T2DM around $13 \%$ (pooled RR $=0.87 ; 95 \%$ CI: 0.82 , 0.93) [9], see Figure 2B. In contrast to whole grains, results from two SRMAs $[9,23]$ suggested that a high intake of refined grains was not associated with risk of T2DM.

For nuts and legume intake, both highest versus lowest and dose-response analyses (e.g., every 4 servings per week or $50 \mathrm{~g}$ per day increase in consumption of legumes) did not suggest a significant benefit of legumes for T2DM prevention $[9,25,26]$ (Figure 2B), while evidence for nuts intake was inconsistent. Findings from both highest versus lowest and dose-response analysis of Schwingshackl et al. [9] suggested no benefits of nuts for prevention of T2DM, whereas results from Afshin et al. indicated that every four servings per week increase in intake of nuts significantly lowered risk of T2DM with pooled RR of 0.87 (95\% CI: 0.81, 0.94) [26].

\section{Dairy Products}

Three SRMAs of cohort studies $[8,10,11]$ assessed the effect of high-fat and low-fat dairy products, milk, cheese, and yogurt on the risk of T2DM. For high and low-fat dairy products, every $200 \mathrm{~g}$ per day increase in an intake or high intake of low-fat dairy products significantly decreased risk of T2DM with pooled RRs ranging from 0.83 (95\% CI: 76, 0.90) to 0.96 (95\% CI: 0.92, 1.00), while high intake of high-fat dairy products and milk were not associated with the risk of T2DM. A high intake of cheese and yogurt significantly lowered the risk of T2DM (Figure 2A).

Fish and Meat

Results from three SRMAs $[9,27,28]$ did not reflect the benefit of high fish intake in lowering the risk of T2DM (Figure 2A). Finding from dose response analysis also indicate the non-significant benefit of regular consumption of fish in prevention of T2DM (Figure 2B).

Two SRMAs of cohort studies $[9,29]$ assessed the association between red and processed meat consumption and the risk of T2DM. These two SRMAs found that high intake of red and processed meat significantly increased the risk of T2DM with pooled RR of 1.21 (95\% CI: 1.13, 1.30) for red meat and pooled RR ranging from 1.27 (95\% CI: 1.20, 1.35) to 1.41 (95\% CI: 1.25, 1.60) for processed meat. In addition, every $100 \mathrm{~g} /$ day increase in intake of red meat and $50 \mathrm{~g} /$ day increase in intake of processed meat also significantly increased the risk of T2DM with pooled RRs of $1.17(95 \%$ CI: $1.08,1.26)$ and 1.37 (95\% CI: 1.22, 1.55), respectively.

\section{Egg, Olive Oil, Chocolate}

Results from one SRMA of cohort [9] studies suggest that high intake of egg did not significantly decrease the risk of T2DM but high and every intake of olive oil $10 \mathrm{~g}$ /day significantly lowered the risk of T2DM with pooled RRs of 0.84 (95\% CI: 0.77, 0.92) and 0.91 (95\% CI: 0.87, 0.95), respectively (Figure 2A,B). One SRMA of cohort studies [30] also found that high and every two servings/week increase in intake of chocolate had significant benefits for the prevention of T2DM (Figure 2 and Supplementary Table S4).

\section{Sugar Sweetened Beverages and Coffee}

Two SRMAs of cohorts [9,31] assessed the effects of sugar and artificial sugar-sweetened beverages on risk of T2DM and one SRMA [32] investigated the effect of coffee drinking. 
Both dose response and high versus low analyses suggested that intake of sugar sweetened beverages was associated with increased risk of T2DM with pooled RRs of 1.31 (95\% CI: 1.20, 1.40) for high intake and 1.21 (95\% CI: 1.12-1.31) for every intake of $250 \mathrm{~mL} /$ day [9]. Furthermore, every 1 serving/day increase in the consumption of artificial SSB significantly increased the risk of T2DM with the pooled RR of 1.25 (1.18-1.33) [31]. By contrast, coffee drinking was associated with 35\% reduction in risk of T2DM when compared highest versus lowest consumption with pooled RR of 0.65 (95\% CI: 0.54-0.78) [32] (Figure 2A,B).

\subsubsection{Food Nutrients}

Eleven SRMAs of cohort studies and one SRMA of RCTs evaluated the effect of food nutrients on risk of T2DM. Almost all SRMAs were conducted in general population, and one SRMA of RCTs was conducted in patients with hypertension or cardiovascular diseases. Food nutrients were divided into fiber (3 SRMAs), magnesium (4 SRMAs), flavonoid (2 SRMA), and n-3 polyunsaturated fatty acid (PUFA) (3 SRMAs). Characteristics of eight SRMAs are presented in Supplementary Table S3 and the effect of each food nutrients on the risk of T2DM are presented in Supplementary Table S4 and Figure 3.

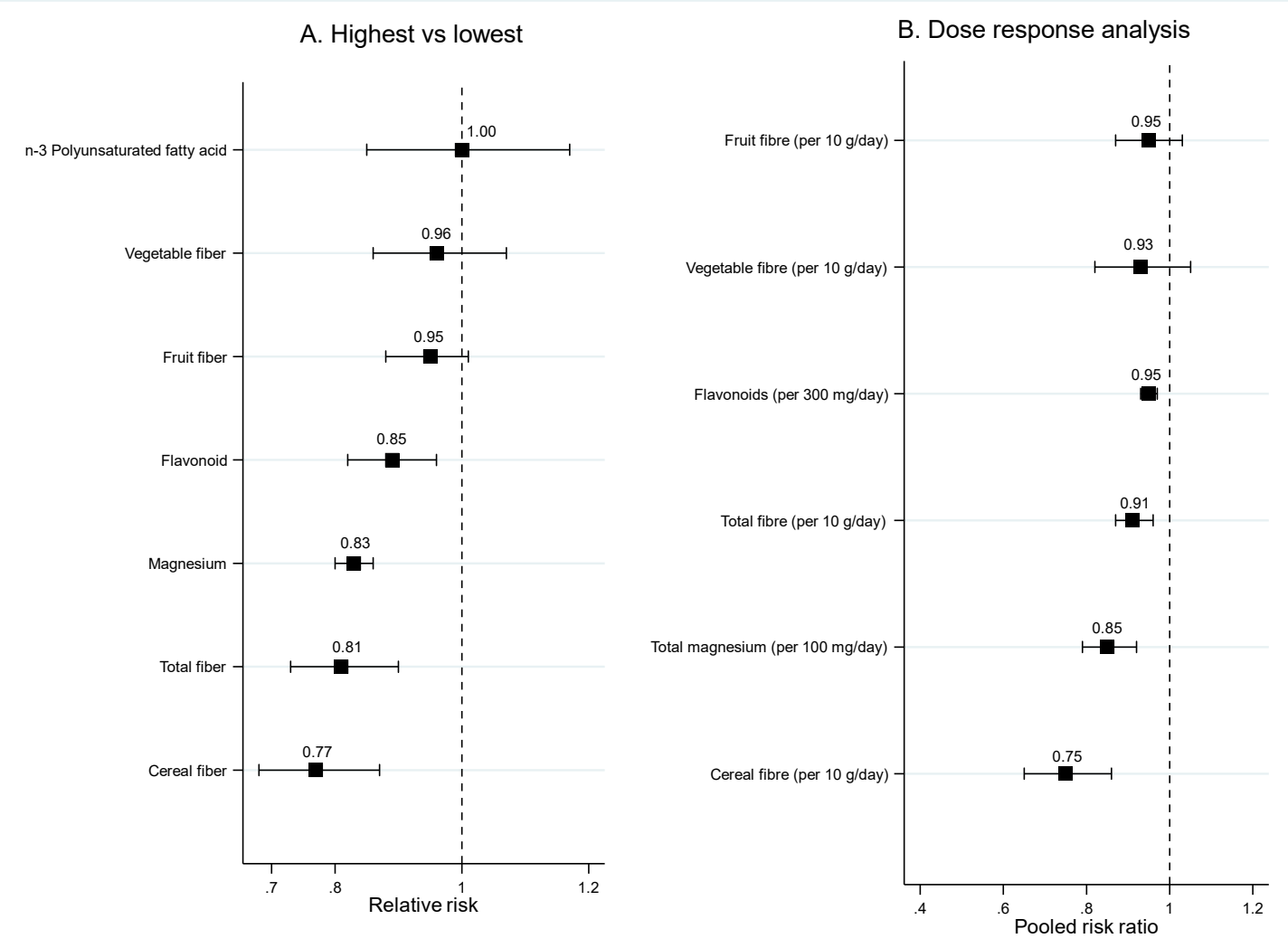

Figure 3. Pooled risk ratios of food nutrients and risk of T2DM. (A) Highest versus lowest category comparison. (B) Dose response analysis.

Fiber

Findings from two SRMAs indicated that a high intake of fiber significantly reduced the risk of T2DM with pooled RRs ranging from 0.81 (95\% CI: 0.73, 0.90) [33] to 0.85 (95\% CI: 0.77, 0.94) [34], see Figure 3A. Results from dose-response analysis also found that every $10 \mathrm{~g} /$ day increase in intake of fiber significantly reduced the risk of T2DM around 9\% (95\% CI: 4\%, 13\%) [33], see Figure 3B. However, when assessed the effect of high fruit and vegetable fiber intake, there was no significant benefit of both fruit and vegetable fiber in the prevention of T2DM [33-35] but a high intake of cereal fiber significantly decreased the risk of T2DM (Supplementary Table S4). 
Magnesium, Flavonoid, n-3 PUFA

Four [35-38] and one [39] SRMA found that high intake of magnesium and flavonoid significantly decreased the risk of T2DM with pooled RRs ranging from 0.77 (95\% CI: $0.72,0.84)$ to 0.83 (95\% CI: 0.80, 0.86) for high intake and pooled RR of 0.89 (95\% CI: 0.82, 0.96) for dose response analysis (Figure 3A,B). However, one SRMA that assessed the effect of flavan-3-osl, a subclass of dietary flavonoid did not find the significant benefit of this subclass for the prevention of T2DM [40]. According to n-3PUFA, results from all three SRMAs did not show the significant benefit of a high intake of n-3 PUFA in prevention of T2DM [41-43].

\subsubsection{Dietary Patterns}

Dietary patterns were eating styles, including Mediterranean diet, DASH diet, low glycemic index diet, or diet with high healthy eating index (HEI), or alternative healthy eating index (AHEI). The effects of dietary patterns were assessed by 10 SRMAs of cohorts (see Figure 4, Supplementary Table S4). Among them, three SRMAs [44-46] indicated that high glycemic index and glycemic load diets were associated with a higher risk of developing T2DM, with the pooled RRs of 1.08 (95\% CI: 1.02, 1.15) to 1.16 (95\% CI: 1.06, 1.26). This result was similar in either highest versus lowest or dose-response analyses. In contrast, Mediterranean $(n=4)$ and DASH diet showed protective effects on T2DM with the pooled RRs ranging from 0.77 (95\% CI: 0.66, 0.89) [47] to 0.87 (95\% CI: 0.82, 0.93) [48] and 0.73 (95\% CI: 0.65, 0.83) [49] to 0.79 (95\% CI: 0.66, 0.95) [50], respectively. Likewise, diet with high HEI and AHEI [48,50] also showed protective effects with the pooled RRs of 0.82 (95\% CI: 076, 0.88) to 0.82 (95\% CI: 0.74, 0.92) [48] and 0.77 (95\% CI: 0.68, 0.86) to 0.79 (95\% CI: 0.70, 0.89), respectively. Four SRMAs [48-51] quantified the effects of adherence to a healthy diet which was classified by factor analysis or principal component analysis. Pooled RRs varied from 0.86 (95\% CI: 0.82, 0.90) to 0.78 (95\% CI: $0.72,0.85)$.
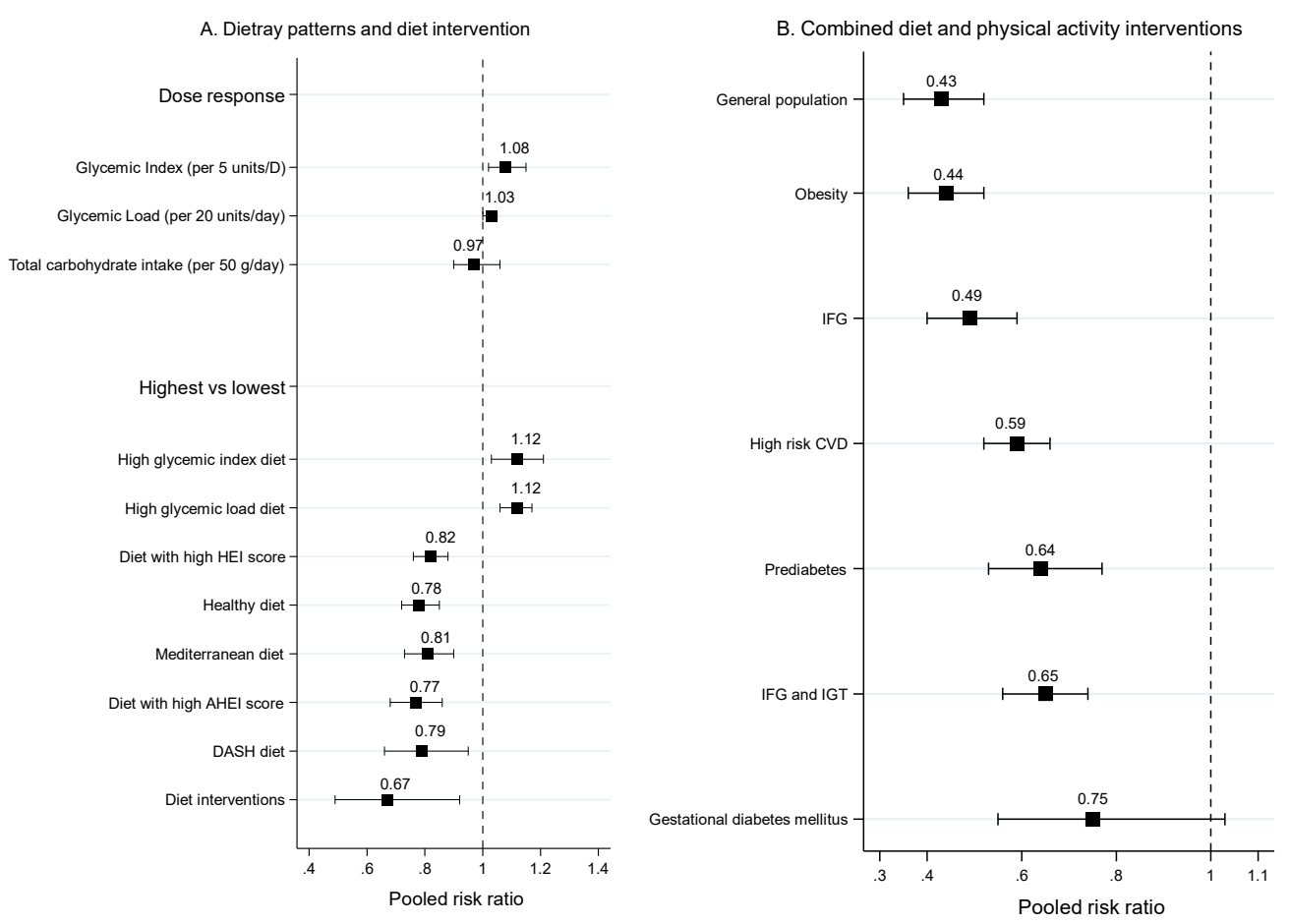

Figure 4. Pooled risk ratios of dietary patterns, diet and combined diet and physical activity interventions and risk of T2DM. (A) Dietary patterns and diet intervention. (B) Combined diet and physical activity interventions. 


\subsubsection{Overlapping of Studies and Excess Significant Finding in Dietary Factors}

The number of included studies in SRMAs for each intervention are described in Supplementary Table S5. A degree of study overlapping or corrected covered area (CCA) of each SRMA was estimated, which ranged from $6.2 \%$ to $11.7 \%$. CCAs were moderate for pooling of food group (CCA $=6.2 \%)$ and dietary patterns $(\mathrm{CCA}=9.7 \%)$; and high for food nutrients $(\mathrm{CCA}=11.7 \%$ ).

The excess significant finding (ESF) was calculated in 11 comparisons of exposure. Seven out of 11 comparisons showed evidence of ESF (Supplementary Table S4). In which, 4 and 3 comparisons were in dietary patterns and food groups, respectively.

\subsection{Diet Intervention}

Four SRMAs of RCTs assessed the effect of diet interventions [16,52-54] on T2DM risk. Characteristics of these SRMAs are described in Supplementary Table S3. Only people at risk such as those with impaired glucose tolerance (IGT), impaired fasting glucose (IFG), or obesity were included in the studies of diet interventions [16,53]. Details of diet intervention prescribed in the RCTs are described in Supplementary Table S6. Diet interventions in most studies were low calories diet (i.e., 25-30 kcal/kg or carbohydrate $<120$ g/day), and American Heart Association's Step II diet (defined as fat intake of $\leq 30 \%$ of total energy, dietary saturated fat to $<10 \%$ of energy and cholesterol to $<300 \mathrm{mg} /$ day). None of the additional behavioral intervention or supporting device was applied to these diet interventions. The duration of follow-up ranged from 1.5 to 9.4 years. Results of the included SRMAs suggest that dietary interventions could significantly lower the risk of T2DM in a high-risk population with pooled RRs ranging from 0.51 (95\% CI: 0.39, 0.68) to $0.71(95 \%$ CI: 0.55, 0.90) (see Figure 4A, Supplementary Table S4).

\subsection{Combination of Diet and Physical Activity Interventions}

Seventeen SRMAs of RCTs [3-6,16,52-63] reported the effects of combined diet and physical activity interventions in the prevention of T2DM. Diet interventions were mainly low calories and carbohydrates, high fiber, or diet control in general. Physical activity, mainly supervised by healthcare professionals, included aerobic exercise, resistance training, or encouragement to increase physical activity. Additionally, pedometers were also used to monitor compliance $[3,58,59,64]$ (Supplementary Table S6). The duration of intervention and follow-up ranged from 6 months to 23 years. Most meta-analyses focused on high-risk people including obesity, metabolic syndrome, IGT, IFG, and women with a history of gestational diabetes mellitus (GDM). Included studies were conducted in various settings, with two reviews focusing in Asian population [58,62] (Supplementary Table S3).

Combined effect of diet and physical activity interventions significantly decreased risk of T2DM in both general and high-risk population with pooled RRs ranging from 0.43 (95\% CI: $0.35,0.52)$ to 0.55 (95\% CI: 0.44, 0.70) for general population [52,58]. For obese people, pooled RRs was 0.44 (95\% CI: 0.36, 0.52) [6] and for people with high-risk of CVDs pooled RRs ranging from 0.35 (95\% CI: 0.14-0.85) [3] to 0.59 (95\% CI: 0.52, 0.66) [56]. For people with prediabetes (e.g., impaired fasting glucose and impaired glucose tolerance test), combined diet and physical activity interventions significantly decreased the risk of T2DM with pooled RRs ranging from 0.39 (95\% CI: $0.28,0.53)$ to 0.65 (95\% CI: $0.56,0.75)$. (Figure 4B, Supplementary Table S4). Results were inconsistent in women with a history of GDM. A study by Goveia et al. [60] did not find significant benefits of combined diet and physical activity interventions, but findings from Li et al. [61] indicated that combined interventions significantly decreased the risk of T2DM around 43\% (pooled RR $=0.57 ; 95 \% \mathrm{CI}: 0.42,0.78$ ).

The overlapping among the included meta-analyses of combined diet and physical activity interventions was moderate (10.6\%) (Supplementary Table S5). The ESF was calculated in 14 comparisons, in which 13 comparisons showed evidence of excess significant finding (Supplementary Table S4). 


\subsection{Methodological Quality of Studies}

Results of quality assessment are presented in Supplementary Table S7. Confidence in the findings of included SRMAs are critically low, low, moderate, and high at $81.7 \%, 15.0 \%, 1.7 \%$, and $1.7 \%$, respectively. Most of SRMAs that had critically low confidence of their findings because they did not adhere to these following critical domains-(1) did not mention established review methods before conducting the review (80\%), (2) did not provide the list and justification of excluded studies (86\%), and (3) did not account for the risk of bias in individual studies when interpreting results (94\%). Moreover, most reviews did not report funding sources of included studies as well as justified the study design included in the reviews.

\section{Discussion}

This umbrella review provides a summary of dietary factors, diet intervention, and combined diet and physical activity interventions and their effects on the risk of T2DM. We found that: (1) diet and combined diet and physical activity interventions significantly decreased the risk of T2DM in both general and high-risk population; (2) dietary patterns such as Mediterranean and DASH diets, a diet with high HEI, and AHEI scores were also beneficial in the prevention of T2DM; (3) among various dietary factors, only a couple of food groups and specific nutrients demonstrated the beneficial effects such as whole grain, low-fat dairy product, cheese, yogurt, olive oil, total fiber, dietary magnesium, and flavonoids; (4) unhealthy diets such as high consumption of high glycemic index and glycemic load diet, red meat and processed meat, sugar and artificial sweetened beverages can accelerate the development of T2DM.

Diabetes develops progressively as a result of the complex interaction between insulin resistance and beta cells dysfunction. Dietary inputs influence the glucose-insulin homeostasis and thus also affect the level of blood sugar. For instance, low-calories and low carbohydrate diets that aim to reduce body weight, a well-known associated factor of insulin resistance had beneficial effects on insulin sensitivity and blood sugar level $[65,66]$. Our review supported this hypothesis as our findings found that dietary interventions that were low calories and low carbohydrate diets (i.e., 25-30 kcal/kg or carbohydrate $<120 \mathrm{~g} /$ day) significantly lower the risk of T2DM in both general and high-risk population. In the pathogenesis of T2DM, both the amount of carbohydrates and also the quality of carbohydrates play an important role. Good quality carbohydrates such as diet with low glycemic index or high complex carbohydrates are associated with increased insulin sensitivity [67] and improved beta-cell function [68]. These have been supported by the results from our review where diets with low glycemic index significantly decreased the risk of T2DM. In addition to macronutrients, micronutrients such as fiber also affect the glucose-insulin homeostasis in human bodies. High fiber intake can improve whole-body insulin sensitivity by increasing colonic production of the short-chain fatty acid acetate, propionate, and butyrate that are the significant end products of dietary fiber fermentation by the gut bacteria $[69,70]$. Several clinical trials found that high fiber intake prevents weight gain [71] and improves markers of insulin sensitivity [72]. Findings from our review correspond with these evidence that increasing fiber intake significantly decreased the risk of T2DM.

Although some food nutrients such as dietary fiber, flavonoids, and magnesium had a significant benefit for T2DM prevention, recent dietary recommendations focus on overall dietary patterns rather than single isolated nutrients because of the limitations of single-nutrient component approach. For instance, matrix of foods, food processing, and food preparation is very complicated and can strongly modify the food nutrients that finally impact the health effects. In addition, translation of nutrient-based recommendations to the public is difficult because the accurate estimation of food nutrients is too complex for the general population.

Dietary patterns, or combination of regularly consumed foods, can produce synergistic health effects not only by decreasing calories but also through metabolic propensity toward abdominal adiposity particularly visceral fat, which in turn influences the insulin response [73]. In addition, evidence also showed that dietary interventions such as low carbohydrate and low glycemic index, 
low fat, and low consumption of sugar sweetened beverages can reduce body weight and visceral fat $[74,75]$. Furthermore, a diet containing low carbohydrate and low glycemic index illustrated the improvement in beta cells function in IGT patients [76].

American Diabetes Association guideline recommends a dietary strategy for subjects with prediabetes such as Mediterranean diet, low-calories, and low-fat eating diet [77]. These eating styles can be translated into specific food groups. Mediterranean diet, for example, involving high in vegetables, fruits, legumes, nuts, beans, cereals, grains, fish, and unsaturated fats such as olive oil. Also, it usually includes a low intake of meat and dairy foods [78]. ADA guideline also recommends that the overall quality of food consumed (as measured by the AHEI), with an emphasis on whole grains, legumes, nuts, fruits and vegetables, and minimal refined and processed foods, is also important [77]. In this study, we confirm this by showing the protective effects of healthy eating styles (e.g., Mediterranean diet, DASH diet, and diet with high HEI, and AHEI index) and multiple food groups. We have pointed out that some particular types of "healthy foods" showing benefits such as green leafy vegetables and cruciferous vegetables. This result does not necessarily mean that only these food groups are beneficial. However, it does suggest that there is substantial uncertainty about other food groups and further research is needed to identify new food groups which are beneficial for prevention of disease.

Physical activity can slow or delay the progression of T2DM by directly increase insulin sensitivity and indirectly strengthen weight control. Moderate to vigorous-intensity physical activity improves beta cells function and glucose regulation, independent of obesity [79-81]. ADA recommends people at risk of T2DM should increase the physical activity to at least $150 \mathrm{~min} /$ week of moderate-intensified activity (e.g., brisk walking) [77]. Our findings show that combined diet and physical activity interventions significantly lowered risk of T2DM and the effect of combined interventions might be superior than the effect of diet intervention alone.

Sugar sweetened beverages significantly increased the risk of T2DM. Recently, artificial sugar sweeteners have emerged as an alternative for sugar sweetened beverages. However, findings from human trial suggested that continuous exposure to artificial sugar sweeteners could reduce acute insulin response, decrease insulin sensitivity, and enhance GLP-1 release in healthy subjects [82]. In addition, recent evidence showed that artificial sugar sweeteners have small beneficial effects on decreasing body mass index and fasting blood glucose [83]. Our review also found that artificial sugar sweetened beverages were associated with higher risk of T2DM. However, this finding comes from only one meta-analysis of cohort study. Future research, therefore, needs to strengthen this claim. We also found that higher consumption of coffee was shown to reduce 35\% of the risk of T2DM compared to lower consumption. Again, this should be reconfirmed by further researches as there are variations in coffee types as well as the way of making coffee in which whether sugar or milk was added.

\section{Strengths and Limitations}

Our study was the first umbrella review systematically summarizing broad evidence of dietary factors, diet intervention, and combined diet and physical activity interventions in the prevention of T2DM. Moreover, our umbrella review assessed the overlapping and excess significant finding among included meta-analyses. This provides evidence on the quality of previous reviews.

As a limitation of the study, we did not consider the primary individual included studies-instead, the results were considered only from SRMAs. Comparisons of effects among interventions is impossible. Moreover, the quality of the included SRMAs was low based on AMSTAR's criteria [13]. This can lead to potential bias in the results of SRMAs. The overlapping in the included meta-analyses were mostly moderate and high, indicating that the included SRMAs could not much add in new evidence. In addition, only two databases without grey or unpublished literature were searched to identify the relevant studies. Therefore, publication bias might be presented in our review.

Most included studies in SRMAs were mainly from developed countries, the transferability of results into specific local context is questionable as the food components of certain diets such as 
Mediterranean diet are not often consumed in other regions. Therefore, future studies should consider the application and effects of these dietary patterns on other geographical areas. In addition, the results from excess significant findings showed that meta-analyses among this group might overestimate the real effect size of the intervention. Therefore, the interpretation of results in these meta-analyses should be cautioned. Given the fact that almost all reviews included in this umbrella review have low confidence in the evidence, an updated meta-analysis that adheres to the criteria of AMSTAR 2 is needed.

Other than diet interventions, pharmacological interventions have shown significant benefits in preventing T2DM especially in high-risk individuals such as people with IFG and IGT [53]. However, the scope of this review did not cover the efficacy of medication treatments and therefore, the comparative effectiveness between lifestyle and pharmacological interventions cannot be assessed in our review. Although, the results from previous systematic review and network meta-analysis that compared the efficacy among all available lifestyle and pharmacological interventions found that glipizide and diet intervention plus pioglitazone had the highest probabilities of being the most effective interventions for T2DM prevention [16]. Potential risk and benefit together with cost-effectiveness of drug treatments relative to lifestyle interventions should be considered when making clinical and policy recommendations.

\section{Conclusions}

In summary, healthy dietary patterns such as Mediterranean, DASH, and diet with the low glycemic index, diet interventions including low calorie and low-fat diets, and combined diet and physical activity interventions, and low consumption of red/processed meat, and sugar sweetened beverages significantly decreased the risk of T2DM. These lifestyle modifications should be promoted in both individual and population levels to prevent and decrease the burden of T2DM in the future.

Supplementary Materials: The following are available online at http://www.mdpi.com/2072-6643/12/9/2722/s1, Supplementary Table S1: Search terms and search strategies in PubMed. Supplementary Table S2: Search terms and search strategies in Scopus. Supplementary Table S3: Characteristics of included systematic reviews and meta-analyses. Supplementary Table S4: Summary results of included systematic reviews and meta-analyses. Supplementary Table S5: Detail of intervention in systematic reviews and meta-analyses of RCTs. Supplementary Table S6: Quality assessment of included studies by AMSTAR 2.

Author Contributions: Conceptualization, T.A., S.R., and P.L.T.; methodology, T.A., A.T., U.C., and P.L.T.; formal analysis, P.L.T. and T.A.; investigation, P.L.T., J.R.B., T.A., U.C., A.T.; writing-original draft preparation, P.L.T. and T.A.; writing-review and editing, P.L.T., J.R.B., T.A., U.C., S.R., and A.T.; supervision, T.A., U.C., and A.T. All authors have read and agreed to the published version of the manuscript.

Funding: This research received no external funding.

Acknowledgments: This work is a part of training in Health Technology Assessment (HTA)'s PhD degree, which scholarship is provided by Mahidol University and the International Decision Support Initiative (iDSI). This work was produced as part of the International Decision Support Initiative (www.idsihealth.org), which supports countries to get the best value for money from health spending. iDSI receives funding support from the Bill \& Melinda Gates Foundation, the UK Department for International Development, and the Rockefeller Foundation. The findings, interpretations and conclusions expressed in this article do not necessarily reflect the views of the aforementioned funding agencies.

Conflicts of Interest: The authors declare no conflict of interest.

\section{References}

1. International Diabetes Federation. IDF Diabetes Atlast-8th Edition; Karuranga, S., Fernandes, J.D.R., Huang, Y., Malanda, B., Eds.; International Diabetes Federation: Brussels, Belgium, 2017.

2. Beckman, J.A.; Paneni, F.; Cosentino, F.; Creager, M.A. Diabetes and vascular disease: Pathophysiology, clinical consequences, and medical therapy: Part II. Eur. Heart J. 2013, 34, 2444-2452. [CrossRef]

3. Schellenberg, E.S.; Dryden, D.M.; Vandermeer, B.; Ha, C.; Korownyk, C. Lifestyle interventions for patients with and at risk for type 2 diabetes: A systematic review and meta-analysis. Ann. Intern. Med. 2013, 159, 543-551. [CrossRef] 
4. Hemmingsen, B.; Gimenez-Perez, G.; Mauricio, D.; Roqué i Figuls, M.; Metzendorf, M.I.; Richter, B. Diet, physical activity or both for prevention or delay of type 2 diabetes mellitus and its associated complications in people at increased risk of developing type 2 diabetes mellitus. Cochrane Database Syst. Rev. 2017, CD003054. [CrossRef]

5. Glechner, A.; Harreiter, J.; Gartlehner, G.; Rohleder, S.; Kautzky, A.; Tuomilehto, J.; Van Noord, M.; Kaminski-Hartenthaler, A.; Kautzky-Willer, A. Sex-specific differences in diabetes prevention: A systematic review and meta-analysis. Diabetologia 2014, 58, 242-254. [CrossRef]

6. Merlotti, C.; Morabito, A.; Ceriani, V.; Pontiroli, A.E. Prevention of type 2 diabetes in obese at-risk subjects: A systematic review and meta-analysis. Acta Diabetol. 2014, 51, 853-863. [CrossRef]

7. Tong, X.; Dong, J.Y.; Wu, Z.W.; Li, W.; Qin, L.Q. Dairy consumption and risk of type 2 diabetes mellitus: A meta-analysis of cohort studies. Eur. J. Clin. Nutr. 2011, 65, 1027-1031. [CrossRef]

8. Aune, D.; Norat, T.; Romundstad, P.; Vatten, L.J. Dairy products and the risk of type 2 diabetes: A systematic review and dose-response meta-analysis of cohort studies. Am. J. Clin. Nutr. 2013, 98, 1066-1083. [CrossRef]

9. Schwingshackl, L.; Hoffmann, G.; Lampousi, A.M.; Knuppel, S.; Iqbal, K.; Schwedhelm, C.; Bechthold, A.; Schlesinger, S.; Boeing, H. Food groups and risk of type 2 diabetes mellitus: A systematic review and meta-analysis of prospective studies. Eur. J. Epidemiol. 2017, 32, 363-375. [CrossRef] [PubMed]

10. Gijsbers, L.; Ding, E.L.; Malik, V.S.; de Goede, J.; Geleijnse, J.M.; Soedamah-Muthu, S.S. Consumption of dairy foods and diabetes incidence: A dose-response meta-analysis of observational studies. Am. J. Clin. Nutr. 2016, 103, 1111-1124. [CrossRef] [PubMed]

11. Chen, M.; Sun, Q.; Giovannucci, E.; Mozaffarian, D.; Manson, J.E.; Willett, W.C.; Hu, F.B. Dairy consumption and risk of type 2 diabetes: 3 cohorts of US adults and an updated meta-analysis. BMC Med. 2014, 12, 215. [CrossRef] [PubMed]

12. Moher, D.; Liberati, A.; Tetzlaff, J.; Altman, D.G. Preferred reporting items for systematic reviews and meta-analyses: The PRISMA statement. PLoS Med. 2009, 6, e1000097. [CrossRef]

13. Shea, B.J.; Reeves, B.C.; Wells, G.; Thuku, M.; Hamel, C.; Moran, J.; Moher, D.; Tugwell, P.; Welch, V.; Kristjansson, E.; et al. AMSTAR 2: A critical appraisal tool for systematic reviews that include randomised or non-randomised studies of healthcare interventions, or both. BMJ (Clin. Res. Ed.) 2017, 358, j4008. [CrossRef] [PubMed]

14. Pieper, D.; Antoine, S.L.; Mathes, T.; Neugebauer, E.A.; Eikermann, M. Systematic review finds overlapping reviews were not mentioned in every other overview. J. Clin. Epidemiol. 2014, 67, 368-375. [CrossRef] [PubMed]

15. Ioannidis, J.P.; Trikalinos, T.A. An exploratory test for an excess of significant findings. Clin. Trials (Lond. Engl.) 2007, 4, 245-253. [CrossRef] [PubMed]

16. Stevens, J.W.; Khunti, K.; Harvey, R.; Johnson, M.; Preston, L.; Woods, H.B.; Davies, M.; Goyder, E. Preventing the progression to type 2 diabetes mellitus in adults at high risk: A systematic review and network meta-analysis of lifestyle, pharmacological and surgical interventions. Diabetes Res. Clin. Pract. 2015, 107, 320-331. [CrossRef]

17. Cooper, A.J.; Forouhi, N.G.; Ye, Z.; Buijsse, B.; Arriola, L.; Balkau, B.; Barricarte, A.; Beulens, J.W.; Boeing, H.; Buchner, F.L.; et al. Fruit and vegetable intake and type 2 diabetes: EPIC-InterAct prospective study and meta-analysis. Eur. J. Clin. Nutr. 2012, 66, 1082-1092. [CrossRef]

18. Wang, P.Y.; Fang, J.C.; Gao, Z.H.; Zhang, C.; Xie, S.Y. Higher intake of fruits, vegetables or their fiber reduces the risk of type 2 diabetes: A meta-analysis. J. Diabetes Investig. 2016, 7, 56-69. [CrossRef]

19. Hamer, M.; Chida, Y. Intake of fruit, vegetables, and antioxidants and risk of type 2 diabetes: Systematic review and meta-analysis. J. Hypertens. 2007, 25, 2361-2369. [CrossRef]

20. Carter, P.; Gray, L.J.; Troughton, J.; Khunti, K.; Davies, M.J. Fruit and vegetable intake and incidence of type 2 diabetes mellitus: Systematic review and meta-analysis. BMJ (Clin. Res. Ed.) 2010, 341, c4229. [CrossRef]

21. Li, S.; Miao, S.; Huang, Y.; Liu, Z.; Tian, H.; Yin, X.; Tang, W.; Steffen, L.M.; Xi, B. Fruit intake decreases risk of incident type 2 diabetes: An updated meta-analysis. Endocrine 2015, 48, 454-460. [CrossRef]

22. Ye, E.Q.; Chacko, S.A.; Chou, E.L.; Kugizaki, M.; Liu, S. Greater whole-grain intake is associated with lower risk of type 2 diabetes, cardiovascular disease, and weight gain. J. Nutr. 2012, 142, 1304-1313. [CrossRef] [PubMed] 
23. Aune, D.; Norat, T.; Romundstad, P.; Vatten, L.J. Whole grain and refined grain consumption and the risk of type 2 diabetes: A systematic review and dose-response meta-analysis of cohort studies. Eur. J. Epidemiol. 2013, 28, 845-858. [CrossRef] [PubMed]

24. De Munter, J.S.; Hu, F.B.; Spiegelman, D.; Franz, M.; van Dam, R.M. Whole grain, bran, and germ intake and risk of type 2 diabetes: A prospective cohort study and systematic review. PLoS Med. 2007, 4, e261. [CrossRef] [PubMed]

25. Tang, J.; Wan, Y.; Zhao, M.; Zhong, H.; Zheng, J.S.; Feng, F. Legume and soy intake and risk of type 2 diabetes: A systematic review and meta-analysis of prospective cohort studies. Am. J. Clin. Nutr. 2020, 111, 677-688. [CrossRef]

26. Afshin, A.; Micha, R.; Khatibzadeh, S.; Mozaffarian, D. Consumption of nuts and legumes and risk of incident ischemic heart disease, stroke, and diabetes: A systematic review and meta-analysis. Am. J. Clin. Nutr. 2014, 100, 278-288. [CrossRef]

27. Wu, J.H.; Micha, R.; Imamura, F.; Pan, A.; Biggs, M.L.; Ajaz, O.; Djousse, L.; Hu, F.B.; Mozaffarian, D. Omega-3 fatty acids and incident type 2 diabetes: A systematic review and meta-analysis. Br. J. Nutr. 2012, 107, S214-S227. [CrossRef]

28. Zhou, Y.; Tian, C.; Jia, C. Association of fish and n-3 fatty acid intake with the risk of type 2 diabetes: A meta-analysis of prospective studies. Br. J. Nutr. 2012, 108, 408-417. [CrossRef]

29. Aune, D.; Ursin, G.; Veierod, M.B. Meat consumption and the risk of type 2 diabetes: A systematic review and meta-analysis of cohort studies. Diabetologia 2009, 52, 2277-2287. [CrossRef]

30. Yuan, S.; Li, X.; Jin, Y.; Lu, J. Chocolate consumption and risk of coronary heart disease, stroke, and diabetes: A meta-analysis of prospective studies. Nutrients 2017, 9, 688. [CrossRef]

31. Imamura, F.; O'Connor, L.; Ye, Z.; Mursu, J.; Hayashino, Y.; Bhupathiraju, S.N.; Forouhi, N.G. Consumption of sugar sweetened beverages, artificially sweetened beverages, and fruit juice and incidence of type 2 diabetes: Systematic review, meta-analysis, and estimation of population attributable fraction. Br. J. Sports Med. 2016, 50, 496-504. [CrossRef]

32. Van Dam, R.M.; Hu, F.B. Coffee consumption and risk of type 2 diabetes: A systematic review. JAMA 2005, 294, 97-104. [CrossRef] [PubMed]

33. The InterAct Consortium. Dietary fibre and incidence of type 2 diabetes in eight European countries: The EPIC-InterAct Study and a meta-analysis of prospective studies. Diabetologia 2015, 58, 1394-1408. [CrossRef] [PubMed]

34. Yao, B.; Fang, H.; Xu, W.; Yan, Y.; Xu, H.; Liu, Y.; Mo, M.; Zhang, H.; Zhao, Y. Dietary fiber intake and risk of type 2 diabetes: A dose-response analysis of prospective studies. Eur. J. Epidemiol. 2014, 29, 79-88. [CrossRef] [PubMed]

35. Schulze, M.B.; Schulz, M.; Heidemann, C.; Schienkiewitz, A.; Hoffmann, K.; Boeing, H. Fiber and magnesium intake and incidence of type 2 diabetes: A prospective study and meta-analysis. Arch. Intern. Med. 2007, 167, 956-965. [CrossRef] [PubMed]

36. Larsson, S.C.; Wolk, A. Magnesium intake and risk of type 2 diabetes: A meta-analysis. J. Intern. Med. 2007, 262, 208-214. [CrossRef] [PubMed]

37. Fang, X.; Han, H.; Li, M.; Liang, C.; Fan, Z.; Aaseth, J.; He, J.; Montgomery, S.; Cao, Y. Dose-Response Relationship between Dietary Magnesium Intake and Risk of Type 2 Diabetes Mellitus: A Systematic Review and Meta-Regression Analysis of Prospective Cohort Studies. Nutrients 2016, 8, 739. [CrossRef]

38. Dong, J.Y.; Xun, P.; He, K.; Qin, L.Q. Magnesium intake and risk of type 2 diabetes: Meta-analysis of prospective cohort studies. Diabetes Care 2011, 34, 2116-2122. [CrossRef]

39. Xu, H.; Luo, J.; Huang, J.; Wen, Q. Flavonoids intake and risk of type 2 diabetes mellitus: A meta-analysis of prospective cohort studies. Medicine 2018, 97, e0686. [CrossRef]

40. Raman, G.; Avendano, E.E.; Chen, S.; Wang, J.; Matson, J.; Gayer, B.; Novotny, J.A.; Cassidy, A. Dietary intakes of flavan-3-ols and cardiometabolic health: Systematic review and meta-analysis of randomized trials and prospective cohort studies. Am. J. Clin. Nutr. 2019, 110, 1067-1078. [CrossRef]

41. Zheng, J.S.; Huang, T.; Yang, J.; Fu, Y.Q.; Li, D. Marine N-3 polyunsaturated fatty acids are inversely associated with risk of type 2 diabetes in Asians: A systematic review and meta-analysis. PLoS ONE 2012, 7, e44525. [CrossRef]

42. Muley, A.; Muley, P.; Shah, M. ALA, fatty fish or marine $\mathrm{n}-3$ fatty acids for preventing DM? A systematic review and meta-analysis. Curr. Diabetes Rev. 2014, 10, 158-165. [CrossRef] [PubMed] 
43. Brown, T.J.; Brainard, J.; Song, F.; Wang, X.; Abdelhamid, A.; Hooper, L. Omega-3, omega-6, and total dietary polyunsaturated fat for prevention and treatment of type 2 diabetes mellitus: Systematic review and meta-analysis of randomised controlled trials. BMJ 2019, 366, 14697. [CrossRef] [PubMed]

44. Dong, J.Y.; Zhang, L.; Zhang, Y.H.; Qin, L.Q. Dietary glycaemic index and glycaemic load in relation to the risk of type 2 diabetes: A meta-analysis of prospective cohort studies. Br. J. Nutr. 2011, 106, 1649-1654. [CrossRef] [PubMed]

45. Greenwood, D.C.; Threapleton, D.E.; Evans, C.E.; Cleghorn, C.L.; Nykjaer, C.; Woodhead, C.; Burley, V.J. Glycemic index, glycemic load, carbohydrates, and type 2 diabetes: Systematic review and dose-response meta-analysis of prospective studies. Diabetes Care 2013, 36, 4166-4171. [CrossRef] [PubMed]

46. Bhupathiraju, S.N.; Tobias, D.K.; Malik, V.S.; Pan, A.; Hruby, A.; Manson, J.E.; Willett, W.C.; Hu, F.B. Glycemic index, glycemic load, and risk of type 2 diabetes: Results from 3 large US cohorts and an updated meta-analysis. Am. J. Clin. Nutr. 2014, 100, 218-232. [CrossRef] [PubMed]

47. Koloverou, E.; Esposito, K.; Giugliano, D.; Panagiotakos, D. The effect of Mediterranean diet on the development of type 2 diabetes mellitus: A meta-analysis of 10 prospective studies and 136,846 participants. Metab. Clin. Exp. 2014, 63, 903-911. [CrossRef] [PubMed]

48. Jannasch, F.; Kröger, J.; Schulze, M.B. Dietary patterns and Type 2 diabetes: A systematic literature review and meta- analysis of prospective studies. J. Nutr. 2017, 147, 1174-1182. [CrossRef]

49. Esposito, K.; Chiodini, P.; Maiorino, M.I.; Bellastella, G.; Panagiotakos, D.; Giugliano, D. Which diet for prevention of type 2 diabetes? A meta-analysis of prospective studies. Endocrine 2014, 47, 107-116. [CrossRef]

50. Schwingshackl, L.; Hoffmann, G. Diet quality as assessed by the Healthy Eating Index, the Alternate Healthy Eating Index, the Dietary Approaches to Stop Hypertension score, and health outcomes: A systematic review and meta-analysis of cohort studies. J. Acad. Nutr. Diet. 2015, 115, 780-800.e785. [CrossRef]

51. Maghsoudi, Z.; Ghiasvand, R.; Salehi-Abargouei, A. Empirically derived dietary patterns and incident type 2 diabetes mellitus: A systematic review and meta-analysis on prospective observational studies. Public Health Nutr. 2016, 19, 230-241. [CrossRef]

52. Merlotti, C.; Morabito, A.; Pontiroli, A.E. Prevention of type 2 diabetes; a systematic review and meta-analysis of different intervention strategies. DiabetesObes. Metab. 2014, 16, 719-727. [CrossRef] [PubMed]

53. Gillies, C.L.; Abrams, K.R.; Lambert, P.C.; Cooper, N.J.; Sutton, A.J.; Hsu, R.T.; Khunti, K. Pharmacological and lifestyle interventions to prevent or delay type 2 diabetes in people with impaired glucose tolerance: Systematic review and meta-analysis. BMJ (Clin. Res. Ed.) 2007, 334, 299. [CrossRef] [PubMed]

54. Yamaoka, K.; Nemoto, A.; Tango, T. Comparison of the Effectiveness of Lifestyle Modification with Other Treatments on the Incidence of Type 2 Diabetes in People at High Risk: A Network Meta-Analysis. Nutrients 2019, 11, 1373. [CrossRef] [PubMed]

55. Hopper, I.; Billah, B.; Skiba, M.; Krum, H. Prevention of diabetes and reduction in major cardiovascular events in studies of subjects with prediabetes: Meta-analysis of randomised controlled clinical trials. Eur. J. Cardiovasc. Prev. Rehabil. Off. J. Eur. Soc. Cardiol. Work. Groups Epidemiol. Prev. Card. Rehabil. Exerc. Physiol. 2011, 18, 813-823. [CrossRef]

56. Balk, E.M.; Earley, A.; Raman, G.; Avendano, E.A.; Pittas, A.G.; Remington, P.L. Combined Diet and Physical Activity Promotion Programs to Prevent Type 2 Diabetes Among Persons at Increased Risk: A Systematic Review for the Community Preventive Services Task Force. Ann. Intern. Med. 2015, 163, 437-451. [CrossRef]

57. Selph, S.; Dana, T.; Blazina, I.; Bougatsos, C.; Patel, H.; Chou, R. Screening for type 2 diabetes mellitus: A systematic review for the U.S. Preventive Services Task Force. Ann. Intern. Med. 2015, 162, 765-776. [CrossRef]

58. Modesti, P.A.; Galanti, G.; Cala', P.; Calabrese, M. Lifestyle interventions in preventing new type 2 diabetes in Asian populations. Intern. Emerg. Med. 2016, 11, 375-384. [CrossRef]

59. Glechner, A.; Keuchel, L.; Affengruber, L.; Titscher, V.; Sommer, I.; Matyas, N.; Wagner, G.; Kien, C.; Klerings, I.; Gartlehner, G. Effects of lifestyle changes on adults with prediabetes: A systematic review and meta-analysis. Prim. Care Diabetes 2018, 12, 393-408. [CrossRef]

60. Goveia, P.; Cañon-Montañez, W.; De Paula Santos, D.; Lopes, G.W.; Ma, R.C.W.; Duncan, B.B.; Ziegelman, P.K.; Schmidt, M.I. Lifestyle intervention for the prevention of diabetes in women with previous gestational diabetes mellitus: A systematic review and meta-analysis. Front. Endocrinol. 2018, 9, 583. [CrossRef] 
61. Li, N.; Yang, Y.; Cui, D.; Li, C.; Ma, R.C.W.; Li, J.; Yang, X. Effects of lifestyle intervention on long-term risk of diabetes in women with prior gestational diabetes: A systematic review and meta-analysis of randomized controlled trials. Obes. Rev. 2020,1-8. [CrossRef]

62. Pang, B.; Zhao, L.H.; Li, X.L.; Song, J.; Li, Q.W.; Liao, X.; Feng, S.; Zhao, X.Y.; Zheng, Y.J.; Gou, X.W.; et al. Different intervention strategies for preventing type 2 diabetes mellitus in China: A systematic review and network meta-analysis of randomized controlled trials. Diabetes Obes. Metab. 2018, 20, 718-722. [CrossRef] [PubMed]

63. Uusitupa, M.; Khan, T.A.; Viguiliouk, E.; Kahleova, H.; Rivellese, A.A.; Hermansen, K.; Pfeiffer, A.; Thanopoulou, A.; Salas-Salvadó, J.; Schwab, U.; et al. Prevention of Type 2 Diabetes by Lifestyle Changes: A Systematic Review and Meta-Analysis. Nutrients 2019, 11, 2611. [CrossRef] [PubMed]

64. Pedersen, A.L.W.; Terkildsen Maindal, H.; Juul, L. How to prevent type 2 diabetes in women with previous gestational diabetes? A systematic review of behavioural interventions. Prim. Care Diabetes 2017, 11, 403-413. [CrossRef]

65. Ajala, O.; English, P.; Pinkney, J. Systematic review and meta-analysis of different dietary approaches to the management of type 2 diabetes. Am. J. Clin. Nutr. 2013, 97, 505-516. [CrossRef] [PubMed]

66. Wheeler, M.L.; Dunbar, S.A.; Jaacks, L.M.; Karmally, W.; Mayer-Davis, E.J.; Wylie-Rosett, J.; Yancy, W.S., Jr. Macronutrients, food groups, and eating patterns in the management of diabetes: A systematic review of the literature, 2010. Diabetes Care 2012, 35, 434-445. [CrossRef]

67. Riccardi, G.; Rivellese, A.A. Effects of dietary fiber and carbohydrate on glucose and lipoprotein metabolism in diabetic patients. Diabetes Care 1991, 14, 1115-1125. [CrossRef]

68. Juanola-Falgarona, M.; Salas-Salvadó, J.; Ibarrola-Jurado, N.; Rabassa-Soler, A.; Díaz-López, A.; Guasch-Ferré, M.; Hernández-Alonso, P.; Balanza, R.; Bulló, M. Effect of the glycemic index of the diet on weight loss, modulation of satiety, inflammation, and other metabolic risk factors: A randomized controlled trial. Am. J. Clin. Nutr. 2014, 100, 27-35. [CrossRef]

69. Macfarlane, S.; Macfarlane, G.T. Regulation of short-chain fatty acid production. Proc. Nutr. Soc. 2003, 62, 67-72. [CrossRef]

70. Flint, H.J.; Scott, K.P.; Duncan, S.H.; Louis, P.; Forano, E. Microbial degradation of complex carbohydrates in the gut. Gut Microbes 2012, 3, 289-306. [CrossRef]

71. Ludwig, D.S.; Pereira, M.A.; Kroenke, C.H.; Hilner, J.E.; Van Horn, L.; Slattery, M.L.; Jacobs, D.R., Jr. Dietary fiber, weight gain, and cardiovascular disease risk factors in young adults. JAMA 1999, 282, 1539-1546. [CrossRef]

72. Robertson, M.D.; Bickerton, A.S.; Dennis, A.L.; Vidal, H.; Frayn, K.N. Insulin-sensitizing effects of dietary resistant starch and effects on skeletal muscle and adipose tissue metabolism. Am. J. Clin. Nutr. 2005, 82, 559-567. [CrossRef]

73. De Mutsert, R.; Gast, K.; Widya, R.; de Koning, E.; Jazet, I.; Lamb, H.; le Cessie, S.; de Roos, A.; Smit, J.; Rosendaal, F; et al. Associations of Abdominal Subcutaneous and Visceral Fat with Insulin Resistance and Secretion Differ Between Men and Women: The Netherlands Epidemiology of Obesity Study. Metab. Syndr. Relat. Disord. 2018, 16, 54-63. [CrossRef] [PubMed]

74. Yoshimura, E.; Kumahara, H.; Tobina, T.; Matsuda, T.; Ayabe, M.; Kiyonaga, A.; Anzai, K.; Higaki, Y.; Tanaka, H. Lifestyle intervention involving calorie restriction with or without aerobic exercise training improves liver fat in adults with visceral adiposity. J. Obes. 2014, 2014, 197216. [CrossRef] [PubMed]

75. Morari, A.; Moraris, E.; Adramerina, A.; Neocleous, C. The effect of eating behavior modification on visceral fat level in individuals with normal body mass index (BMI). Clin. Nutr. Espen 2016, 13, e62. [CrossRef]

76. Wolever, T.M.; Mehling, C. High-carbohydrate-low-glycaemic index dietary advice improves glucose disposition index in subjects with impaired glucose tolerance. Br. J. Nutr. 2002, 87, 477-487. [CrossRef] [PubMed]

77. American Diabetes Association. 3. Prevention or Delay of Type 2 Diabetes: Standards of Medical Care in Diabetes-2019. Diabetes Care 2019, 42, S29-S33. [CrossRef] [PubMed]

78. Willett, W.C.; Sacks, F.; Trichopoulou, A.; Drescher, G.; Ferro-Luzzi, A.; Helsing, E.; Trichopoulos, D. Mediterranean diet pyramid: A cultural model for healthy eating. Am. J. Clin. Nutr. 1995, 61, 1402S-1406S. [CrossRef] [PubMed] 
79. Chen, Z.; Black, M.H.; Watanabe, R.M.; Trigo, E.; Takayanagi, M.; Lawrence, J.M.; Buchanan, T.A.; Xiang, A.H. Self-reported physical activity is associated with beta-cell function in Mexican American adults. Diabetes Care 2013, 36, 638-644. [CrossRef] [PubMed]

80. Malin, S.K.; Gerber, R.; Chipkin, S.R.; Braun, B. Independent and combined effects of exercise training and metformin on insulin sensitivity in individuals with prediabetes. Diabetes Care 2012, 35, 131-136. [CrossRef]

81. Slentz, C.A.; Tanner, C.J.; Bateman, L.A.; Durheim, M.T.; Huffman, K.M.; Houmard, J.A.; Kraus, W.E. Effects of exercise training intensity on pancreatic beta-cell function. Diabetes Care 2009, 32, 1807-1811. [CrossRef]

82. Lertrit, A.; Srimachai, S.; Saetung, S.; Chanprasertyothin, S.; Chailurkit, L.O.; Areevut, C.; Katekao, P.; Ongphiphadhanakul, B.; Sriphrapradang, C. Effects of sucralose on insulin and glucagon-like peptide-1 secretion in healthy subjects: A randomized, double-blind, placebo-controlled trial. Nutr. (BurbankLos Angeles Cty. Calif.) 2018, 55, 125-130. [CrossRef] [PubMed]

83. Toews, I.; Lohner, S.; Kullenberg de Gaudry, D.; Sommer, H.; Meerpohl, J.J. Association between intake of non-sugar sweeteners and health outcomes: Systematic review and meta-analyses of randomised and non-randomised controlled trials and observational studies. BMJ (Clin. Res. Ed.) 2019, 364, 1156. [CrossRef] [PubMed]

(C) 2020 by the authors. Licensee MDPI, Basel, Switzerland. This article is an open access article distributed under the terms and conditions of the Creative Commons Attribution (CC BY) license (http://creativecommons.org/licenses/by/4.0/). 